\title{
Hydatid Disease - A Clinical Perspective with A Review of Primary Hydatidosis of Spleen
}

Kapil Rampal ${ }^{*}{ }^{1}$, Devendra K. Prajapati ${ }^{1}$, Meghna Sharma ${ }^{2}$.

${ }^{* 1}$ Senior Residents, Deen Dayal Upadhyaya Hospital , New Delhi-64

2 Medical officer, CHC Kasel, Tarn Taran.

\section{ABSTRACT}

Hydatid cyst disease is a zoonotic infection with Echinococcus sp as the causative agent. $M$ an is an accidental dead end host. It can affect any organ of body most common being the liver. Primary infection of spleen is rare. Treatment modalities include medical, surgical and combined.

KEY WORDS: Echinococcus, Hydatid Cyst, Splenic Hydatidosis, Albendazole, PAIR.

Address for correspondence: Dr. Kapil Rampal, F9/431, Street No 5 , Gokal Avenue, Amritsar., Punjab, India. E-Mail: balkarankapil@gmail.com

\begin{tabular}{|c|c|c|}
\hline \multicolumn{3}{|c|}{ Online Access and Article Informtaion } \\
\hline $\begin{array}{l}\text { Quick Response code } \\
\text { 品 }\end{array}$ & $\begin{array}{r}\text { International Jour } \\
\text { wu }\end{array}$ & $\begin{array}{l}\text { tegrative Medical Sciences } \\
\text { sciences.com }\end{array}$ \\
\hline 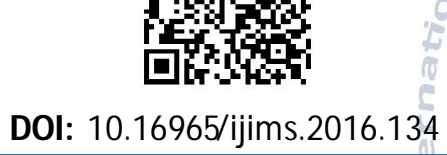 & $\begin{array}{l}\text { Received: } 20-06-2016 \\
\text { Reviewed: } 20-06-2016\end{array}$ & $\begin{array}{l}\text { Accepted: 19-07-2016 } \\
\text { Published: 31-07-2016 }\end{array}$ \\
\hline
\end{tabular}

\section{INTRODUCTION AND ETIOPATHOGENESIS}

Hydatid disease is zoonotic infectious disease caused by the larval forms of Echinococcus species (most common being granulosum). It is a considerable health problem in endemic areas( cattle rearing areas) [1,2]. Humans are accidental dead end hosts. It most frequently localizes to liver (60\%-70\%), and lungs (20\%). Spleen is the third most common organ involved but isolated splenic involvement is rare. Its combined occurrence as isolated affection or concomitant with other organs, is reported to be only about $0.5 \%-0.6 \%$ [3].

M odalities of treatment continue to evolve and include either or combined use of medical and surgical interventions. Surgical interventions have evolved from open surgical techniques to minimally invasive methods. Of the 16 species and 13 sub species described under the genus Echinococcus, only four species are known to be pathogenic and hence clinically relevant. These are E. granulosum,E. multilocul-aris,
Eoligarthrus and E.volgeli. of these Echinococcus granulosum is the most pathological agent.

The life cycle of $E$. granulosum requires to hosts [Figure $1 \& 2$ ]. Adult form inhabits the gut of a definitive host (carnivore) and release eggs that are passed out in faeces and contaminate the soil.

Herbivores get infected by ingesting contaminated food items. Embryos migrate from gut and develop mostly in liver. Spread of embryos via blood can infect any host tissue. For the life cycle to be completed these affected organs need to be eaten by the carnivore definitive host, thus the humans are an accidental dead end hosts [4].

Development of cyst: in the target organ the parasite changes into a cyst and matures. The mature cyst consists of a germinal layer that surrounds a fluid filled central cavity and laminated layer. The germinal and the laminated layers form the endocyst. The compression of 
Diagnosis: Majority of the cases stay asymptomatic for years. One third may have pressure symptoms, complications or non specific complaints. Complications include secondary infection, rupture into pericardium, pleura, biliary tract or pericardium. Pressure symptoms may manifest as obstructive jaundice, portal hypertension, etc $[5,6]$.

Routine laboratory parameters are non specific and within normal limits. Eosinophilia is a feature only in $1 / 4^{\text {th }}$ of the cases. ELISA serology has a sensitivity of $90 \%$ [7].

Radiology: USG and CT are both diagnostic of the disease and also have a role in the follow up of the disease. The WHO classification of the disease is based upon the USG findings [Figure 3].

$\mathrm{CT}$ findings are confirmatory and have a greater role to play in assessment of complications. MR cholangiography in liver hydatidosis can provide greater details of intrahepatic and extrahepatic biliary tree with its relation to the hydatid cyst [8].

Treatment: Chemotherapy: benzimidazole carbamates (albendazole and mebendazole) are the drugs of choice. Cyst viability rates after 03 months of albendazole treatment was found to be only $8 \%[9]$.

Surgical: surgical approaches vary from a wide range of conservative to radical procedures. The conservative methods concentrate upon evacuation of cyst contents while the radical surgeries aim at total cyst excision and may even involve pericystectomy and hepatectomy.

Surgical approaches to both these broad categories may be open or lapaoscopic (minimally invasive). Both techniques stress upon the need to avoid spillage of contents and use of protoscolicidal agents as hypertonic saline, cetrimide+chlorhexidine, absolute alcohol and povidine iodine. Percutaneous techniques dwell upon the principal of PAIR i.e. puncture, aspiration, instillation of protoscolicidal agent and reaspiration. This principal is utilized both in open and minimally invasive techniques. Various authors have reported relapse rates upto $20 \%$ after surgical intervention. ${ }^{10-12} \mathrm{~W}$ ith betterment of skill in minimal access surgery and improvement in equipments, a further betterment of results is expected. A special system developed by Planivelu called the 'Planivelu hydatid system' aims to prevent spillage and allows intracystic visualization of contents [12].

Various authors have advocated techniques as follows, for residual cyst cavities:

\section{Capsulorrhaphy}

2. Capitonnage

3. Omentoplasty

4. Internal collapse

5. Introflexion

6. M yoplasty

\section{Cystogastrostomy/ cystojejunostomy}

8.Marsupialization

Radical surgeries involving liver resection are recommended only for large biliary-cyst fistulae. The basic techniques and principals remain the same for lung hydatidosis and these basic procedures are extrapolated to suit the situation.

Splenic hydatid cyst disease: For this rare affliction total splenectomy, partial splenectomy or resection of a solitary cyst have been reported. Total splenectomy is the preferred approach in large multiple cysts [14,15].

Fig. 1: Showing a Radiological image.

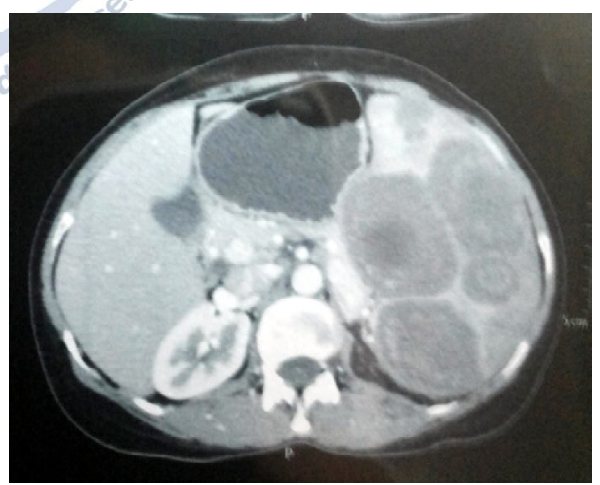

Fig. 2: Showing massive splenomegaly.

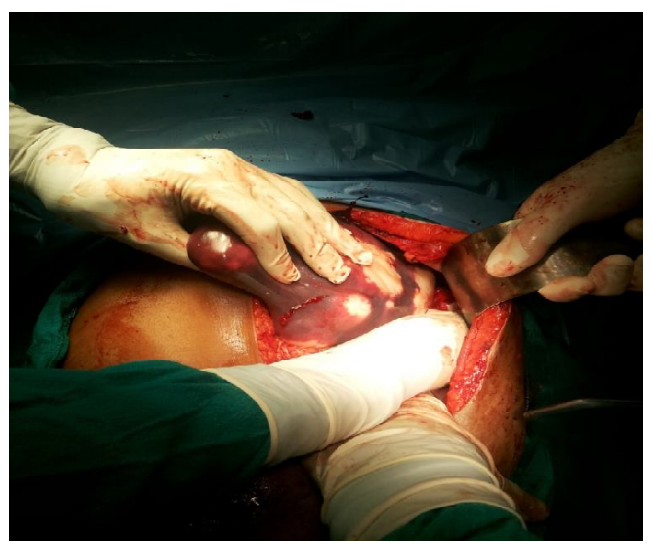


Fig. 3: Showing the massive splenomegaly after resection.

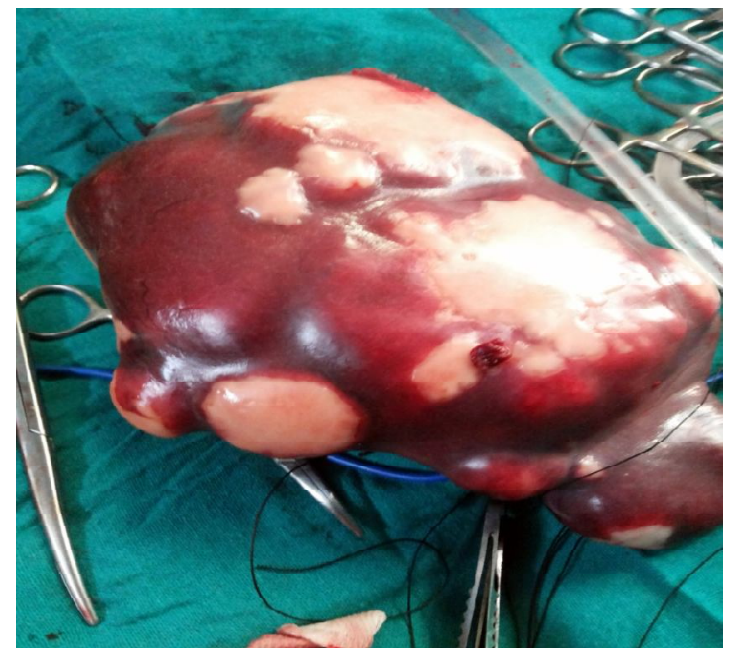

Case: 46 year lady presented to the surgery department with complaints of a painless progressive mass in left upper abdomen in past six months. She also complained of early satiety and progressive weight loss. There was no history of fever, jaundice, gastrointestinal or urinary complaints. Menstrual history was normal. There was no history of any medical comorbidities.

On examination the patient had stable vitals and her general physical examination was within normal limits. Per abdomen examination revealed massive splenomegaly with the spleen reaching the umbilicus in the mid line. Rest of the systemic examination was normal.

Haematological and biochemical investigations were all within normal limits. The ultra sound revealed multiple cysts in an enlarged spleen with multiple daughter cysts likely hydatid cysts. Rest of abdominal organs were normal. Chest $X$-ray was within normal limits. No other chest or abdominal organ looks affected. [Figure 4]

Patient was planned for elective open splenectomy and started on oral albendazole therapy one week prior to surgery. The patient was also vaccinated with Hib, pneumococcal and meningococcal vaccines.

Intra operatively care was taken to ensure zero spillage from any accidental rupture of cysts. Findings included massive splenomegaly measuring $35 \mathrm{~cm} \times 20 \mathrm{~cm}$, hydatid cysts studding the entire spleen surfaces and dense perisplenic adhesions [Figure 5,6].

Histopathological examination confirmed presence of hydatid cyst. Majority of the cysts were non viable and in various stages of calcification. Post operatively albendazole was continued to complete 03 cycles of 28 days each, 05 days apart. Recovery was uneventful and a follow up after 06 months of surgery showed no evidence of recurrence.

\section{DISCUSSION}

Hydatid cyst disease is an endemic disease in Indian subcontinent and mostly affect liver and lungs of victims. Other body parts are affected secondarily as a part of multi organ hydatidosis. Splenic hydatidosis more often presents with a tender/non-tender left upper abdominal mass or splenomegaly with fever. ${ }^{16}$ Reports of anaphylactic reaction following rupture of splenic hydatid cyst have been recorded. ${ }^{17}$ Other cystic diseases like epidermoid cyst, abscess or cystic neoplasms form important differential diagnosis and a careful eye should always be kept for hydatid cyst disease especially in endemic areas [18].

CT scan has higher sensitivity and specificity in diagnosing the condition than USG $[19,20]$. Treatment for splenic hydatid disease can be medical, surgical or combined. Smaller cysts found incidentally can be managed with antihelmenthic therapy alone followed by a close follow up. Surgical methods reported in literature include total splenectomy, partial splenectomy or resection/enucleation of cyst [21]. Total splenectomy is preferred for symptomatic large / multiple cysts [22]. Splenic salvage surgery has a role in paediatric age groups [23-25]. Almatzidis et al had compared total splenectomy with spleen preserving surgery and found no significant difference in short and long term complications [26]. Laparoscopic and robotic surgical approaches are the 'new things in'techniques [27-29].

As we had an extensive hydatidosis of massively enlarged spleen, we went in for open total splenectomy.

\section{CONCLUSION}

Hydatid cyst disease has been extensively reported in literature. However a consensus eludes a common standardized line of management especially for a rarer sub variety i.e. splenic hydatidosis. Total splencectomy 
remains the optimal treatment as the results arre good and replicable in most hands.

\section{Conflicts of interest: None}

\section{REFERENCES}

[1]. Franquet, T., Montes, M., Lecumberri, F.J., Esparza, J., Bescos, J.M. Hydatid disease of the spleen: Imaging finding in nine patients. Am J Roentgenol 1990;154:525-8.

[2]. Huizinga W KJ, Grant CS, Daar AS. Hydatid disease. In:Morris PJ, Wood WC, eds.Oxford Textbook of Surgery. 2nded. New York, NY: Oxford University Press;2000:3298e3305.

[3]. Baraket Oussama, M oussa Makrem, Ayed Karim, Kort Brahim, Ben Moussa Mohamed, Bouchoucha Samy. Surgical treatment and outcomes of hydatid cyst of the spleen. Open Journal of Gastroenterology, 2014;4:51-55.

[4]. Blumgarts surgery of liver, pancreas and biliary tract $5^{\text {th }} \mathrm{Ed}$.

[5]. M ilicevic M. Hydatid disease. In: Blumgart LH, Fong $Y$, eds.Surgery of the Liver and Biliary Tract. 3rd ed. London: Churchill Livingstone; 1994:1121e1150.

[6]. Balik AA, Bas,o_glu M, Celebi F, et al. Surgical treatment of hydatid disease of the liver: review of 304 cases. Arch Surg.1999;134:166e169.

[7]. Lt Col S. Anand, Brig S. Rajagopalan, Sqn Ldr Raj M ohan. Management of liver hydatid cysts e Current perspectives. medical journal armed forces india 2012;68:304-309.

[8]. Little $A F$, et al. MR cholangiography in the evaluation of suspected intrabiliary rupture of hepatic hydatid cyst. Abdom Imaging 2002;27:333-335.

[9]. Wen $\mathrm{H}$, et al. Albendazole chemotherapy for human cystic and alveolar echinococcosis in north-western China. Trans R Soc Trop Med Hyg. 1994;88:340-343.

[10]. Vaquerizo A, Sola JL, Bondia A, Opla JM, Madariaga MJ.Intraoperative hydatid anaphylactic shock. Rev Esp Anestesiol Reanim. 1994;41:113-116.

[11]. Belghiti J, Benhamou JP, Houry S, Grenier P, Huguier $M$, Fekete $F$. Caustic sclerosing cholangitis. A complication of the surgical treatment of hydatid disease of the liver. Arch Surg.1986;121:1162e1165.

[12]. Atmatzidis KS, Pavlidis TE, Papaziogas BT, M irelis C, Papaziogas TB. Recurrence and long-term outcome after open cystectomy with omentoplasty for hepatic hydatid disease in an endemic area. Acta Chir Belg.2005;105:198-202.

[13]. Palanivelu C, Jani Kalpesh, Malladi Vijaykumar, et al. Laparoscopic management of hepatic hydatid disease. JSLS.2006;10(1):56-62.

[14]. Arikanoglu, Z., Taskesen, F. and Gumus, H. Coll electing a surgical modality to treat a splenic hydatid cyst: Total splenectomy or spleen-saving surgery? Journal of Gastrointestinal Surgery, 2012;16:1189-1193.
[15]. Narasimharao, K.L., Venkateswarluk, K., Mitta, S.K. and $M$ etha, S. Hydatid disease of spleen treated by cyst enucleation and splenic salvage. Journal of Pediatric Surgery, 1987;22:138.

[16]. Ionescu A, Jakab A, Jutis T, Forai F, Ota A. Splenic hydatid cyst (Article in Romanian). Rev Med Chir Soc Med Nat lasi.1990;94:525-8.

[17]. Bitton M, Kleiner-Baumgarten A, Peiser J, Barki Y, SukenikS. Anaphylactic shock after traumatic rupture of a splenicechinococcal cyst (article in Hebrew). Harefuah 1992;122:226-8.

[18]. Goel MC, Agarwal MR, Misra A. Percutaneous drainage of renal hydatid cyst:early results and follow-up. Br J Urol 1995;75:724-8.

[19]. Herrera Merino N, Abascal Morte J, Diaz del Rio Botas $M$ et al. Splenic hydatid cyst. A report of 16 cases (Article in Spanish). Ev Esp Enferm Dig 1991;79:254-8.

[20]. Col Hariqbal Singh, Maj Sumeet Arora. Primary Hydatid Cyst of the Spleen. MJAFI 2003;59:169-170

[21]. Fernández-Ruiz, M., Guerra-Vales, J.M., EnguitaValls, A.B., Vila-Santos, J., García-Borda, F.J. and Morales-Gu- tiérrez, C. Splenic hydatid cyst, a rare location of extrahepatic echinococcosis: Report of six cases. Euro- pean Journal of Internal Medicine, 2008;19:51-53.

[22].Gollackner, B., Längle, F., Auer, H., M aier, A., M ittlböck, M., Agstner, I., et al. Radical surgical therapy of abdominal cystic hydatid disease: Factors of recurrence. World Journal of Surgery, 2000;24:717721.

[23]. Atmatzidis, K., Papaziogas, B., M irelis, C., Pavlidis, T. and Papaziogas, T. Splenectomy versus spleenpreser- ving surgery for splenic echinococcosis. Digestive Surgery, 2003;20:527-531.

[24]. Rodríguez-Leal, G.A., M orán-Villota, S., Milke-García and $M$ del, P. Splenic hydatidosis: A rare differential di-agnosis in a cystic lesion of the spleen. Revista de Ga- stroenterología de M éxico, 2007;72:122-125.

[25]. Kaya, B., Uçtum, Y. and Kutanýp, R. Splenic hy- datid cyst attacking retroperitoneum. Türkiye Parazitoloji Dergisi, 2010;34:193-195.

[26]. Cordoba, E., Escartin, J., Cantin, S., Artigas, J.M. and Esarte, J.M. Hydatic cyst of spleen. Journal of Clinical Gastroenterology, 2001;33:89-90.

[27]. Gharaibeh, K.I.A. Laparoscopic excision of sple- nic hydatid cyst. Postgraduate Medical Journal,2001;77:195-196.

[28]. Khoury, G., Abiad, F., Geagea, T., Nabout, G. and Jabbour, A. Laparoscopic treatment of hydatid cysts of the liver and spleen. Surgical Endoscopy, 2000;14:243-245.

[29]. Polat, F.R., Sezer, A. and Polat, S. Laparoscopic treatment of hydatid cyst of the spleen without splenect- omy: Report of a case. Surgical Laparoscopy Endoscopy \& Percutaneous Techniques, 2009;19:e215-e216.

$$
\begin{aligned}
& \text { How to cite this article: } \\
& \text { Kapil Rampal, Devendra K. Prajapati, M eghna Sharma. Hydatid Disease - A } \\
& \text { Clinical Perspective with A Review of Primary Hydatidosis of Spleen. Int J } \\
& \text { Intg M ed Sci 2016;3(7):337-340. DOI: 10.16965/ijims.2016.134 }
\end{aligned}
$$

